\title{
Marketing wearable home baby monitors: real peace of mind?
}

The peace of mind for which parents buy expensive but unregulated wearable monitors, and on which their marketing depends, may be illusory, David King writes

\author{
David King clinical lecturer in paediatrics, Academic Unit of Child Health, University of Sheffield, \\ Sheffield S10 2TH, UK
}

Wearable devices for infants are a growing industry. In April 2014, the US company Owlet announced that it had raised $\$ 1.85 \mathrm{~m}(£ 1.2 \mathrm{~m} ; € 1.5 \mathrm{~m})$ to develop and launch a "smart sock" that can be attached to a newborn baby's ankle to monitor its vital signs. ${ }^{1}$ Parents can use a smart phone to check heart rate, oxygen concentrations, and skin temperature and to receive alerts if the child rolls over.

Owlet's chief executive, Kurt Workman, is ambitious. "We see the wearable future will include every single baby coming home from the hospital with a wearable monitor," he told the Telegraph. ${ }^{1}$ The company states that these devices will give parents "peace of mind and maybe even a full night's sleep."” The product is still in development but can be reserved online for $\$ 250$.

Another company, Rest Devices, has developed Mimo, which is available for $\$ 199.99$. This is a baby grow with inbuilt sensors that monitor a baby's respiratory rate and temperature. ${ }^{3}$

Sproutling is another start-up company aiming to capitalise on this market. It has released details of a device to be worn around a baby's ankle that can monitor heart rate and temperature and will sell at a recommended price of $\$ 299$. $^{4}$

\section{Sudden infant death syndrome}

To older paediatricians this may sound familiar. In the 1980s and 1990s a plethora of similar products was developed and sold with the intention of reducing sudden infant death syndrome (SIDS). Unfortunately epidemiological studies showed that such devices had no effect on the incidence of SIDS in healthy infants. ${ }^{5-7}$ The American Academy of Pediatrics states that home cardiorespiratory monitors should not be used as a strategy to reduce the risk of SIDS. ${ }^{8}$

Home monitoring may be justified in some situations, such as for preterm infants or infants who need oxygen. But in these cases parents and other caregivers should be trained in observation techniques, operation of the monitor, and infant cardiopulmonary resuscitation. ${ }^{9}$
Owlet, Rest Devices, and Sproutling do not claim that their devices reduce the risk of SIDS. However, parental fears about SIDS have driven the development of their products - and the themes in their marketing. Workman, in a press release for the Owlet monitor, said that part of the inspiration for the product was that he "had a cousin pass away from [SIDS]." executive of Sproutling, Chris Bruce, was quoted in Time magazine as saying that the idea for the product arose because he was incessantly checking the baby monitor after the birth of his first child to make sure she was still breathing. ${ }^{11}$

In its promotional video, Owlet shows a mother saying that she is "one of the mums who puts my fingers in front of [my baby's] nose to make sure she is breathing and my hand on her chest to make sure it is going up and down." ${ }^{12}$ Rest Devices does not mention SIDS in its marketing but does state that use of its device gives "relief from that heavy anxious feeling" and "keeps babies safe."”

Both Sproutling and Rest Devices include a disclaimer on their websites to say that there is no evidence that their devices can reduce the risk of SIDS. ${ }^{3}{ }^{4}$ However, in the case of Rest Devices this disclaimer is in small print under its terms of service and is not prominent.

\section{Regulatory approval not needed in the US}

None of these products requires approval from the US Food and Drug Administration. They are not yet available in Europe, and it is unclear whether regulatory approval will be needed here. Owlet and Rest Devices originally wanted their products to be sold as medical devices and were planning to gain FDA approval before launch. However, representatives from both companies have said that the time and expense that this process would have required made it unfeasible. ${ }^{13} 14$

They both acknowledged that they modified their products so that they could sell them direct to consumers without any need to apply to the FDA. Owlet's cofounder Jacob Colvin explained that the alarm was removed so that it could be sold as an 
unregulated monitoring device. ${ }^{12}$ Similarly, Dulcie Madden, head of Rest Devices, said that by removing any alarms and making the Mimo a product for consumers, rather than a medical device, the company could circumvent the need to apply to the FDA for regulatory approval. ${ }^{13}$

Owlet states on its website that the device "alerts you if something appears wrong with your baby's heart rate or the amount of oxygen in his/her body." ${ }^{1}$ Rest Devices claims that its product allows parents to see their "baby's breathing patterns, in real-time." 3 Sproutling says that it will let you know "if your baby is sleeping soundly or if something is wrong." ${ }^{4}$ No published data support any of these claims, and because the devices are being sold as consumer rather than medical devices such data are not required. Ideally, manufacturers would be required to undertake observational studies or randomised trials to support any claims they make concerning the utility and efficacy of wearable devices in infants-even if they are categorised as consumer devices.

But until that time medical professionals and consumers need to be aware that such devices have no proved use in safeguarding infants or detecting health problems, and they certainly have no role in preventing SIDS. Healthcare professionals should not recommend these products to reduce parents' fears of SIDS but should instead focus on interventions that have been proved to work, such as encouraging parents to put infants on their back to sleep. ${ }^{8}$

Despite disclaimers in small print on the companies' websites saying that the products are not medical devices, parents may not be fully aware of the implications of this when spending several hundred dollars on these products. Manufacturers should place prominent disclaimers at the point of sale to emphasise that they are not medical devices and that no evidence shows that they reduce the risk of SIDS or have any other health benefits.

Workman told me that Owlet was planning to place a disclaimer on its website saying that the device did not reduce the risk of SIDS. He was keen to emphasise that its main function was to offer parents "reassurance." In addition, he wished to highlight that some small trials were ongoing and that the company eventually planned to apply for FDA approval. Rest Devices and Sproutling did not reply to my attempts to contact them. Are the manufacturers of these wearable devices for infants being completely transparent with their future customers? If they are not, the risk is that the substantial amounts of money that parents pay for such devices might lull them into a false sense of security.

Competing interests: I have read and understood the BMJ Group policy on declaration of interests and declare the following interests: none

Provenance and peer review: Not commissioned; not externally peer reviewed.

1 Peck S. Baby monitor 2.0 is born: but does it spell the end of maternal instinct? Telegraph 2014 Apr 24. www.telegraph.co.uk/women/mother-tongue/10785072/Baby-monitor-2.0is-born-but-does-it-spell-the-end-of-maternal-instinct.html.

2 Owlet. Introducing the Owlet smart sock. www. owletcare.com. Accessed 10 Nov 2014.

3 Rest Devices. Stay connected with the Mimo baby monitor. http://mimobaby.com. Accessed 10 Nov 2014

4 Sproutling. Meet Sproutling. The smarter baby monitor. www.sproutling.com. Accessed 10 Nov 2014.

5 Hodgman JE, Hoppenbrouwers T. Home monitoring for the sudden infant death syndrome: the case against. Ann NY Acad Sci 1988:533:164-75

6 Ward SL, Keens TG, Chan LS, Chipps BE, Carson SH, Deming DD, et al. Sudden infant death syndrome in infants evaluated by apnea programs in California. Pediatrics 1986;77:451-8.

7 Ramanathan R, Corwin MJ, Hunt CE, Lister G, Tinsley LR, Baird T, et al. Cardiorespiratory events recorded on home monitors: comparison of healthy infants with those at increased risk for SIDS. JAMA 2001:285:2199-207.

8 Task Force on Sudden Infant Death Syndrome, Moon RY. SIDS and other sleep-related infant deaths: expansion of recommendations for a safe infant sleeping environment. Pediatrics 2011;128:e1341-67.

9 Committee on Fetus and Newborn. American Academy of Pediatrics. Apnea, sudden infant death syndrome, and home monitoring. Pediatrics 2003:111:914-7.

10 Owlet Press Release. Owlet baby care creates the first wearable tech for babies, sending heart rate \& oxygen levels to a parent's smartphone. 26 Aug 2013. www.owletcare.com/ Media\%20Kit.zip.

11 Begley S. The Sproutling is like Fitbit for your baby-but better. Time 2014 Aug 7. http:/ time.com/3086806/sproutling-baby-monitor.

12 Owlet Care. Owlet vitals monitor-see your child's heart and oxygen levels on your smartphone. www.youtube.com/watch?v=q-5YDBp63uk.

13 Rollins Center for Entrepreneurship and Technology. IBMC 2013: team Owlet-1st place. www.youtube.com/watch?v=rS6fHW9pRek.

14 Startup Bootcamp. Dulcie Madden (Rest Devices). www.youtube.com/watch?v=GxILsGkRAc.

Cite this as: BMJ 2014;349:96639

๑) BMJ Publishing Group Ltd 2014 